\title{
The cloning and activity of human Hes1 gene promoter
}

\author{
HAI LU ${ }^{1,2}$, JINQUN JIANG ${ }^{3}$ and YI GAO $^{1,4}$ \\ ${ }^{1}$ Department of Hepatobiliary Surgery II, Guangdong Provincial Research Center for Artificial Organ and Tissue Engineering, \\ Guangzhou Clinical Research and Transformation Center for Artificial Liver, Institute of Regenerative Medicine, \\ Zhujiang Hospital, Southern Medical University, Guangzhou, Guangdong 510282; ${ }^{2}$ Department of Breast Surgery; \\ ${ }^{3}$ Clinical Laboratory, Yuebei People's Hospital, Shaoguan, Guangdong 512026; ${ }^{4}$ State Key Laboratory of \\ Organ Failure Research, Southern Medical University, Guangzhou, Guangdong 510282, P.R. China
}

Received June 20, 2017; Accepted September 15, 2017

DOI: $10.3892 / \mathrm{mmr} .2017 .8240$

\begin{abstract}
The aim of the current study was to obtain and analyze the activity of the human Hes1 gene promoter. The genomic DNA of human HeLa cell was used as template, polymerase chain reaction (PCR) was used to amplify the 5 ' end sequence of Hes1 gene and then the amplified segment was connected to pMD18-T vector. Subsequently, double enzyme digestion was used for identification and the sequence was detected; the promoter with the correct sequence was inserted into pGL3-Basic, and the sequence was identified by double enzyme digestion. The recombinant DNA with correct sequence was transiently transfected into cervical cancer cells, and the dual luciferase reporter gene assay system was used to detect the activity of the promoter. The results demonstrated that the human Hes1 gene promoter amplified by PCR was the same as that of the sequence in the gene bank, and the dual luciferase reporter gene assay system demonstrated that there was promoter activity in cervical cancer cells. In conclusion, the Hes1 luciferase reporter recombinant vector was successfully established and transfected into HeLa cells to verify that it has promoter activity, and the core area of the promoter has several tumor-promoting and tumor suppressor genes. This provides a basis for understanding the regulatory mechanism of Hes1 transcription and translation.
\end{abstract}

\section{Introduction}

During the development of normal cells, the proliferation and differentiation remain a dynamic balance, which is important

Correspondence to: $\mathrm{Dr} \mathrm{Yi}$ Gao, Department of Hepatobiliary Surgery II, Guangdong Provincial Research Center for Artificial Organ and Tissue Engineering, Guangzhou Clinical Research and Transformation Center for Artificial Liver, Institute of Regenerative Medicine, Zhujiang Hospital, Southern Medical University, 253 Middle Gongye Avenue, Guangzhou, Guangdong 510282, P.R. China

E-mail: gaoyi6146@163.com

Key words: Hes1 gene, promoter, luciferase reporter gene to the normal physical function of the body $(1,2)$. Among the pathways that regulate the balance of proliferation and differentiation, Notch-Hes is one of the key pathways (3-5). Previous studies have identified that Hes1 protein is extensively expressed in various cell types in adult mice (6-8). The Hes1 gene is an important member of the basic Helix-Loop-Helix gene family, which is abundantly expressed during embryonic development (9-11). It is located at 3q28-q29 on human chromosome 3, the mRNA contains 1,471 base pairs and 4 exons. The Hes1 protein is encoded by the Hes1 gene and contains 280 amino acids and the relative molecular weight is $29,400(12,13)$. As an important downstream effector molecule of the Notch signaling pathway, Hes1 serves an important role in the proliferation and particularly the differentiation of the mammalian cells $(14,15)$. Previously, in the research of cervical caner, it has been identified that Hes1 protein is particularly expressed in the nucleus and cytoplasm of the cervical epithelial cells $(16,17)$. The Hes1 expression levels in the epithelial cells of cervical intraepithelial neoplasia and cervical cancer are significantly increased compared with normal cervical epithelial cells. As the severity of cervical epithelial neoplasia increases, the Hes1 expression is increased (18-20). It was hypothesized that Hes1 protein overexpression may be involved in the carcinogenesis of the cervical epithelium. In the present study, the Hes1 promoter was cloned and the activity was analyzed in order to provide a basis for the research on transcription and regulation of Hes1 during the occurrence and development of cervical cancer.

\section{Materials and methods}

Materials. The human cervical cancer HeLa cell line (Institute for Regenerative Medicine, ZhuJiang Hospital of Southern Medical University, Guangzhou, China), GenBank (National Center for Biotechnology Information, Bethesda, MD USA), Dulbecco's modified Eagle's medium (DMEM; GE Healthcare Life Sciences, Logan, UT, USA), fetal bovine serum (Thermo Fisher Scientific, Inc., Waltham, MA, USA), Ex Taq, T4 DNA ligase, pMD18-T vector, restriction enzymes SacI and HindIII (all from Takara Bio, Inc., Otsu, Japan), primer synthesis (Sangon Biotech Co., Ltd., Shanghai, China), pGL3-Basic vector, PGL3-control vector, PRL-TK vector, dual-luciferase reporter assay kit (all Promega Corporation, Madison, WI, USA), Escherichia coli DH5 $\alpha$ (Institute for Regenerative 
Table I. Hes1 promoter sequences and their associated transcription factors.

\begin{tabular}{|c|c|}
\hline Start point & Sequence $\left(5^{\prime}-3^{\prime}\right)$ \\
\hline-889 & gggattcaagaactaccttgctccgaaaaacctgcatttgtgaggtagaaggcaattttt \\
\hline-829 & cctttttctgcatggaaacaggaaaatttttttggccett ttcctttaccatctactttc \\
\hline-769 & accctcctga atgtaaagtctg ${ }^{*}$ agcgggaactttagatgtgtcggtaactcacattctta \\
\hline \multirow[t]{2}{*}{-709} & caccegtecceceteccecegececettttaaccactgetgtttttttetttattgttt \\
\hline & MZF1 \\
\hline-649 & atacctttaaaaaaatatgtttcaaatgaacttactacagtcaaagcagctctgttaca \\
\hline \multirow[t]{2}{*}{-589} & tatgagagagggcataaagagcaaagaccetggctccaaaagaaatagacaagatcaaga \\
\hline & $\mathrm{CdxA}$ \\
\hline-529 & $\begin{array}{l}\text { ccaaagcggaaagaaaaaaaaaatctctaaaccaaagcccagagggagagagcaaagg } \\
\text { SRY }\end{array}$ \\
\hline-469 & ttaaaatccttttgattgacgttgtagcetccggtgccetgggetcaggcgcgcgccatt \\
\hline-409 & $\begin{array}{c}\text { ggccgccagaccttgtgcctggcggccaatgggggggcgcggtccacgagcggtgccgcg } \\
\text { SP1 }\end{array}$ \\
\hline-349 & tgtctcctcctcccattggctgaaagttactgtggga aagaaagtttgggaagtttcaca \\
\hline & SPY $\quad$ Lyf1 \\
\hline-289 & cgagccgttcgcgtgcagtcccagatatatatagaggccgccagggcctagggatcacac \\
\hline-229 & aggatccggagctggtgetgataacagcggaatcccccgtctacctctctccttggtcct \\
\hline & GATA-1 C-REL \\
\hline-169 & $\frac{\text { ggaacagcgctactgatcaccaagtagccacaaaatataataaacctcagcacttgctc }}{\mathrm{CdxA}}$ \\
\hline-109 & agtagttttgtgaaagtctcaagtaaaagagacacaaacaaaaaattctttttcgtgaag \\
\hline-49 & $\begin{array}{l}\text { aactccaaaaataaaattctctagagataaaaaaaaaaaaaaaaggaaaatgccagctga } \\
\text { GATA-1 }\end{array}$ \\
\hline 12 & tataatggagaaaaattcctcgtccccggtggetgetacccagccagtgtcaacacgac \\
\hline 72 & accggataaaccaaagacagcatctgagcacagaaaggtaagggcggtacctgtatctct \\
\hline 132 & ttgcagcccctcaaaattaag \\
\hline
\end{tabular}

"The area between the stars represents the core sequence. MZF1, myeloid zinc finger 1; Sp1, transcription factor Sp1; CdxA, Caudal-type homeodomain protein A; SRY, sex-determining region Y; Lyf1, lymphoid transcription factor LyF-1; GATA-1, erythroid transcription factor; C-REL, Proto-oncogene c-Rel.

Medicine, ZhuJiang Hospital of Southern Medical University), genomic DNA extraction kit, agarose gel extraction kit, plasmid minipreparation medium kit (DP304; Tiangen Biotech Co., Ltd., Beijing, China), Lipofectamine ${ }^{\mathrm{TM}} 2000$ (Thermo Fisher Scientific Inc.), and electrophoresis-grade agarose (12\% separation gel and 5\% spacer gel) were used.

Cell culture and the extraction of genome. HeLa cells were cultured in high glucose DMEM containing $10 \%$ fetal bovine serum. The cells were maintained at $37^{\circ} \mathrm{C}$, in a saturated humidity and $5 \% \mathrm{CO}_{2}$ incubator, and were passaged every 2-3 days. The cells at the logarithmic phase were used in all the experiments. The TIANamp Genomic DNA kit (DP304) was used to extract the genomic DNA of HeLa cells, and all procedures were conducted according to the manufacturer's protocol (Tiangen Biotech Co., Ltd.).

Amplification of human Hesl gene promoter and the purification of the product. The primer was designed according to the 5'end of Hes1 gene from GenBanksp16 (ncbi.
Table II. Analysis of Hes1 promoter activity following HeLa cell transfection.

\begin{tabular}{|c|c|c|c|c|}
\hline Group & $\mathrm{n}$ & $\begin{array}{c}\text { Relative } \\
\text { luciferase activity }\end{array}$ & F-value & P-value \\
\hline pGL3-Basic & 3 & $1.076 \pm 0.214$ & 84.434 & $<0.001$ \\
\hline pGL3-Hes1-promoter & 3 & $34.44 \pm 13.76$ & & \\
\hline pGL3-Control & 3 & $100.47 \pm 9.13$ & & \\
\hline
\end{tabular}

nlm.nih.gov/nuccore/NT_005612.17?from=100428715\&to= 100434890\&report=genbank). The Hes1 gene sequence was analyzed using BIO-XM ${ }^{\mathrm{TM}}$ (Biomax Informatics AG, Planegg, Germany) and the -747-+66 segment at the 5' end was amplified. The following primers were used: Upstream, 5'-CGA GCTCAGCGGGAACTTTAGATGTG-3' and downstream, 5'-CCCAAGCTTGTTGACACTGGCTGGGGTA-3'. The underlined parts indicate the enzyme sites-SacI and HindIII. The genomic DNA of HeLa cells was used as a template, and 
A

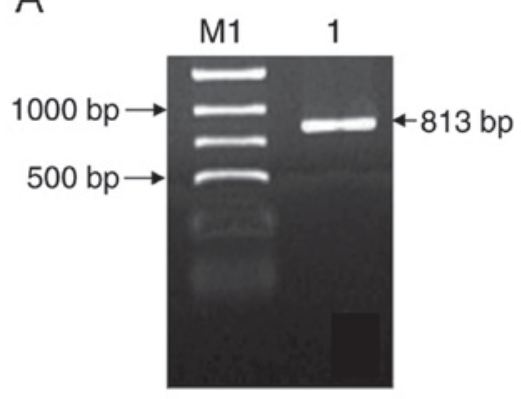

B

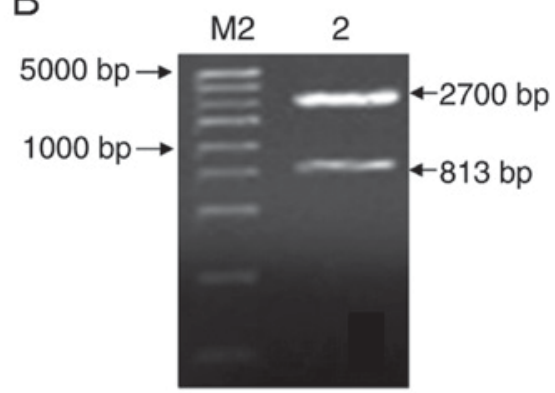

Figure 1. (A) The PCR amplification product and (B) dual-enzyme digestion product of the Hes1 promoter. M1, DNA Marker 2000; M2, DNA Marker 5000; 1, PCR product; 2, the product of recombinant plasmid pMD18-T-Hes1-promoter after SacI and HindIII dual enzyme digestion. PCR, polymerase chain reaction; bp, base pairs.

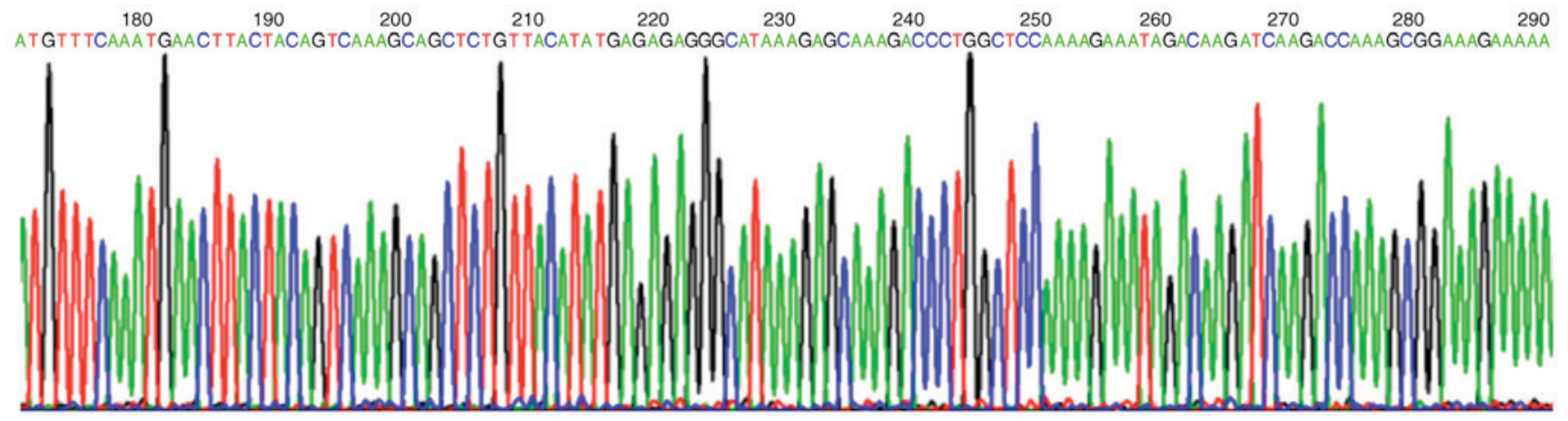

Figure 2. The sequence image of recombinant T cloning vector pMD18-T-Hes1-promoter.

polymerase chain reaction (PCR) was used to amplify the Hes1 promoter segment. The Hes1 promoter sequences are listed in Table I.

The amplification conditions were pre-denaturation at $95^{\circ} \mathrm{C}$ for $5 \mathrm{~min}$, denaturation at $95^{\circ} \mathrm{C}$ for $30 \mathrm{sec}$, annealing at $56.2^{\circ} \mathrm{C}$ for $30 \mathrm{sec}$, elongation at $72^{\circ} \mathrm{C}$ for $45 \mathrm{sec}$, there were 35 cycles in total, followed by elongation at $72^{\circ} \mathrm{C}$ for $10 \mathrm{~min}$. Following PCR, $5 \mu \mathrm{l}$ product was added in $1.5 \%$ agarose gel for electrophoresis. Subsequently, the gel extraction kit was used for the purification of the PCR product. The procedures were conducted according to the manufacturer's protocol [DNA amplification and extraction kit (cat. no. ER103; Tiangen Biotech Co., Ltd.)].

The connection and identification of purified target segment and cloning vector. The collected PCR product (Hes1 gene) was transfected by Lipofectamine ${ }^{\mathrm{TM}} 2000$ into the pMD18-T vector, which was transformed and amplified to extract the plasmids. Subsequently, restriction enzymes for SacI and HindIII dual-enzyme digestion were used and the sequences were detected, which was termed the pMD18-T-Hes1-promoter.

The establishment and identification of recombinant expression vectors. The recombinant $\mathrm{T}$ vector with the correct sequence and pGL3-Basic plasmid received SacI and HindIII dual-enzyme digestion and separated by agarose electrophoresis, the gel extraction kit was used to collect the target segment, and then T4 DNA ligase was used to transform, amplify and extract the plasmids. The product received

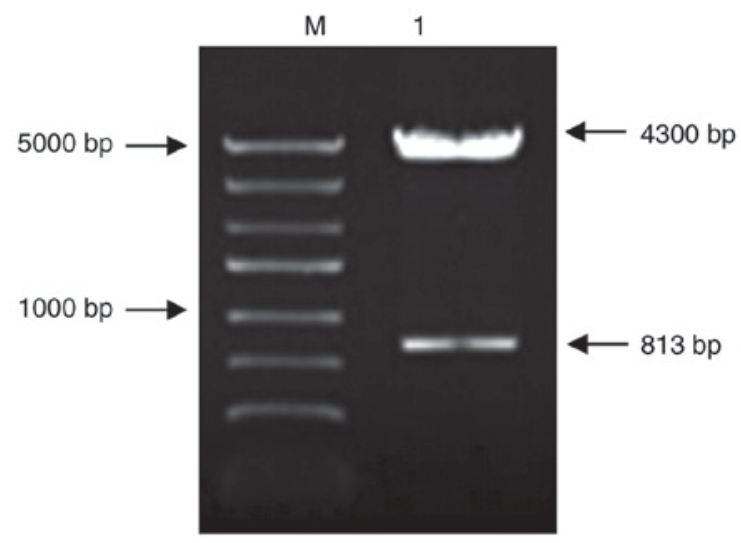

Figure 3. Electrophoresis image of recombinant expression vector after SacI and HindIII dual-enzyme digestion. M, DNA Marker 5000; 1, the dual-enzyme digestion product of recombinant expression vector pGL3-Hes1-promoter. bp, base pairs.

dual-enzyme digestion and sequence detection, which was termed the pGL3-Hes1-promoter.

Transfection of recombinant expression vector into the cells and activity detection. The HeLa cells were inoculated in 24-well plate at $4 \mathrm{~h}$ before transfection, $0.5 \mathrm{ml}$ complete medium and $0.5 \times 10^{5}$ cells were added in each well and the transfection was conducted when the cells reached $70-80 \%$ confluency. The procedures were done according to the manufacturer's instructions for Lipofectamine 2000. The transfected plasmids included negative control plasmid pGL3-Basic, positive control 


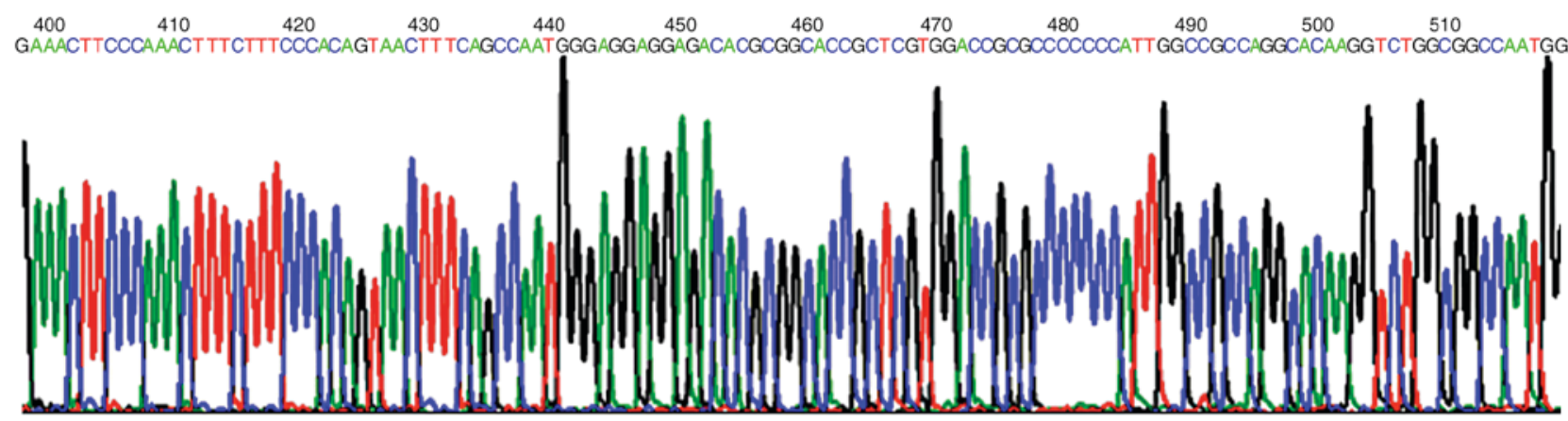

Figure 4. The sequencing image of recombinant expression vector of pGL3-Hes1-promoter.

plasmid pGL3-Control containing the SV40 enhancer/promoter, recombinant plasmid pGL3-Hes1-promoter and internal control PRL-TK plasmid. A total of $48 \mathrm{~h}$ after transfection, the Dual-luciferase reporter assay kit from Promega was used to detect the activity of the transfected plasmid, and there were 3 repeated wells for every group and the experiments were repeated 3 times.

Statistical analysis. The data were analyzed by SPSS software, version 18.0 (SPSS, Inc., Chicago, IL, USA). One-way analysis of variance and the Q test were used to analyze the data. The data were presented as mean \pm standard deviation. $\mathrm{P}<0.05$ was considered to indicate a statistically significant difference.

\section{Results}

Target segment after PCR product electrophoresis. The genomic DNA of HeLa cell was used as a template and the promoter segment of the Hes1 gene was amplified by PCR, and the electrophoresis results indicated that there was a specific band at 813 base pairs (bp), as presented in Fig. 1A.

Enzyme cutting identification of recombinant T cloning vector. The PCR production of the Hes1 promoter was purified and connected to the pMD18-T vector to establish the recombinant vector pMD18-T-Hes1-promoter. Subsequent to transformation the plasmids were extracted for SacI and HindIII dual enzyme digestion. The electrophoresis results demonstrated that there were two specific bands at 813 and 2,700 bp, as presented in Fig. 1B.

Sequence detection of recombinant $T$ cloning vector. DNA sequence analysis demonstrated that compared with the Hes1 gene promoter sequence from GenBank, the 5' and 3' ends of the cloned target segment of recombinant $\mathrm{T}$ cloning vector were located upstream $-747 \mathrm{bp}$ and downstream $+66 \mathrm{bp}$ of ATG, the size was 813 bp as presented in Fig. 2.

Electrophoresis results of recombinant expression vector pGL3-Hesl-promoter after dual enzyme digestion. The electrophoresis of recombinant expression vector pGL3-Hes1-promoter after SacI and HindIII dual-enzyme digestion demonstrated that there were specific bands at 813 and 4,300 bp, as presented in Fig. 3 .
Sequencing results of recombinant expression vector. DNA sequencing results demonstrated that compared with the Hes1 promoter sequence from GenBank, the 5' and 3' end of the target segment sequence of cloned expression vector pGL3-Hes1-promoter located at upstream -747 bp and downstream $+66 \mathrm{bp}$ of ATM, the size was $813 \mathrm{bp}$, as presented in Fig. 4.

Activity analysis of recombinant expression vector following HeLa cell transfection. At $48 \mathrm{~h}$ after HeLa cell transfection by recombinant expression plasmid pGL3-Hes1-promoter, pGL3-Basic and pGL3-Control, the luciferase expression was detected. The ratio of first and second fluorescence was defined as the relative luciferase activity. The relative luciferase of pGL3-Basic was 1.076, of pGL3-Control was 100.47 and of pGL3-Hes1-promoter was 34.44, there was significant difference $(\mathrm{P}<0.05$; Table II).

\section{Discussion}

During the normal development of cells, the proliferation and differentiation remains in dynamic balance, which is important for normal physical function (21-23). The pathways to regulate the balance between cell proliferation and differentiation include the leukemia inhibitory factor-bone morphogenetic protein pathway, octamer-binding transcription factor 3/4 pathway, Wnt pathway and Notch-Hes pathway $(24,25)$. These pathways are composed of various cytokines and transcription factors and among these pathways, the Notch-Hes signaling transduction pathway is the most important pathway. If there is abnormity of Notch signaling pathway, the cells cannot differentiate normally, thus there is possibility of oncogenesis, and it has been reported that the Notch receptor is abnormally expressed in numerous human solid tumor types including cervical, head and neck, endometrial, kidney, lung and breast cancer, pleural mesothelioma and salivary gland tumors) and hematological malignancies (26-28).

Cervical cancer is the second most common type of female malignant cancer, following breast cancer in developing countries and the most common type of genital cancer in Asia (29). The morbidity of cervical cancer is increasing and the mortality is the second highest cause of cancer-associated mortality in women in Asia (29-31). In the early stages of cervical cancer, there is usually no symptoms and the physical signs are not obvious, however early diagnosis and early 
treatment are the key methods to increase the survival rate. Previous studies have demonstrated that the low degree of cell differentiation is associated with poor prognosis (32-34). As an important downstream target gene of Notch signaling pathway, Hes1 genes can directly combine with specific DNAs to block the pathway activation and inhibit cell differentiation $(35,36)$. Thus, exploring the regulatory mechanism of its transcription is significant in the prevention and treatment of cervical cancer.

The regulation of gene expression in eukaryotic cells include transcriptional-level regulation and post-transcriptional regulation according to the sequencing, and transcriptional-level regulation is the predominant method (37). Transcriptional-level regulation is the most important step in the regulation of gene expression in eukaryote, which mainly depends on the effects of certain regulatory sequences (including the promoter and enhancer) and certain protein factors (such as transcription factors) on the initiation of transcription. The key regulation of gene expression is on a transcriptional level, and the promoter is the most important domain in transcriptional regulation. Thus, the study on Hes1 is important. The luciferase reporter gene vector doesn't contain the promoter and enhancer, which can clone the target gene into the expression plasmid vector containing the reporter gene. The expression of luciferase is associated with the promoter sequence in the recombinant plasmid. Subsequent to transfection, the expression of luciferase activity can directly reflect the activity of the promoter. At present, this method is widely applied $(12,13)$. The novelty of the current study is that the promoter sequence was newly designed.

In the current study, the Hes1 luciferase reporter recombinant vector was successfully established and transfected into HeLa cells to verify that it had promoter activity, and the core area of the promoter had several tumor-promoting and tumor suppressor genes. This provides a basis for the further study of the regulatory mechanism of Hesl transcription and translation. In addition, it can provide novel strategy, target and experimental evidence for the prevention and treatment of cervical cancer.

\section{References}

1. Roese-Koerner B, Stappert L and Brustle O: Notch/Hes signaling and miR-9 engage in complex feedback interactions controlling neural progenitor cell proliferation and differentiation. Neurogenesis (Austin) 4: e1313647, 2017.

2. Saclier M, Theret M, Mounier R and Chazaud B: Effects of macrophage conditioned-medium on murine and human muscle cells: Analysis of proliferation, differentiation, and fusion. Methods Mol Biol 1556: 317-327, 2017.

3. Fujimori K, Kadoyama K and Urade Y: Protein kinase C activates human lipocalin-type prostaglandin D synthase gene expression through de-repression of notch-HES signaling and enhancement of AP-2 beta function in brain-derived TE671 cells. J Biol Chem 280: 18452-18461, 2005.

4. Li X, Liu F, Zhang X, Shi G, Ren J, Ji J, Ding L, Fan H, Dou H, and Hou Y: Notch-Hes-1 axis controls TLR7-mediated autophagic death of macrophage via induction of P62 in mice with lupus. Cell Death Dis 7: e2341, 2016.

5. Muranishi Y, Terada K, Inoue T, Katoh K, Tsujii T, Sanuki R, Kurokawa D, Aizawa S, Tamaki Y and Furukawa T: An essentia role for RAX homeoprotein and NOTCH-HES signaling in Otx2 expression in embryonic retinal photoreceptor cell fate determination. J Neurosci 31: 16792-16807, 2011.

6. Hidalgo-Sastre A, Brodylo RL, Lubeseder-Martellato C, Sipos B, Steiger K, Lee M, von Figura G, Grünwald B, Zhong S, Trajkovic-Arsic M, et al: Hes1 Controls Exocrine cell plasticity and restricts development of pancreatic ductal adenocarcinoma in a mouse model. Am J Pathol 186: 2934-2944, 2016.
7. Kayahara T, Sawada M, Takaishi S, Fukui H, Seno H, Fukuzawa H, Suzuki K, Hiai H, Kageyama R, Okano H and Chiba T: Candidate markers for stem and early progenitor cells, Musashi-1 and Hes1, are expressed in crypt base columnar cells of mouse small intestine. FEBS Lett 535: 131-135, 2003.

8. Nakazaki H, Reddy AC, Mania-Farnell BL, Shen YW, Ichi S, McCabe C, George D, McLone DG, Tomita T and Mayanil CS: Key basic helix-loop-helix transcription factor genes Hes1 and Ngn2 are regulated by Pax3 during mouse embryonic development. Dev Biol 316: 510-523, 2008.

9. Barton A and Fendrik AJ: Sustained vs. oscillating expressions of Ngn2, Dll1 and Hes1: A model of neural differentiation of embryonic telencephalon. J Theor Biol 328: 1-8, 2013.

10. Lee JB, Werbowetski-Ogilvie TE, Lee JH, McIntyre BA, Schnerch A, Hong SH, Park IH, Daley GQ, Bernstein ID and Bhatia M: Notch-HES1 signaling axis controls hemato-endothelial fate decisions of human embryonic and induced pluripotent stem cells. Blood 122: 1162-1173, 2013.

11. Sturrock M, Hellander A, Matzavinos A and Chaplain MA: Spatial stochastic modelling of the Hesl gene regulatory network: Intrinsic noise can explain heterogeneity in embryonic stem cell differentiation. J R Soc Interface 10: 20120988, 2013.

12. Sturrock M, Hellander A, Aldakheel S, Petzold L and Chaplain MA: The role of dimerisation and nuclear transport in the Hes1 gene regulatory network. Bull Math Biol 76: 766-798, 2014.

13. Zhang K, Zhang YQ, Ai WB, Hu QT, Zhang QJ, Wan LY, Wang XL, Liu CB and Wu JF: Hes1, an important gene for activation of hepatic stellate cells, is regulated by Notch1 and TGF- $\beta /$ BMP signaling. World J Gastroenterol 21: 878-887, 2015.

14. Min XH, Yu T, Qing Q, Yuan YH, Zhong W, Chen GC, Zhao LN, Deng N, Zhang LF and Chen QK: Abnormal differentiation of intestinal epithelium and intestinal barrier dysfunction in diabetic mice associated with depressed Notch/NICD transduction in Notch/Hes1 signal pathway. Cell Biol Int 38: 1194-1204, 2014.

15. Shi Y, Shu B, Yang R, Xu Y, Xing B, Liu J, Chen L, Qi S, Liu X, Wang P, et al: Erratum to: Wnt and Notch signaling pathway involved in wound healing by targeting c-Myc and Hes1 separately. Stem Cell Res Ther 6: 254, 2015.

16. Wang Z, Li Y, Banerjee S and Sarkar FH: Emerging role of Notch in stem cells and cancer. Cancer Lett 279: 8-12, 2009.

17. Suprasert P, Srisomboon J, Siriaunkgul S, Khunamornpong S, Phongnarisorn C, Siriaree S, Charoenkwan K, Cheewakriangkrai $\mathrm{C}$ and Kietpeerakool C: Clinical outcomes and prognostic factors of node-negative cervical cancer patients with deep stromal invasion or lymphovascular space involvement following radical hysterectomy. J Med Assoc Thai 89: 1368-1375, 2006.

18. Liu J, Lu WG, Ye F, Cheng XD, Hong D, Hu Y, Chen HZ and Xie X: Hes1/Hes5 gene inhibits differentiation via down-regulating Hash1 and promotes proliferation in cervical carcinoma cells. Int J Gynecol Cancer 20: 1109-1116, 2010.

19. Liu J, Ye F, Chen H, Lü W, Zhou C and Xie X: Expression of differentiation associated protein Hes1 and Hes5 in cervical squamous carcinoma and its precursors. Int J Gynecol Cancer 17: 1293-1299, 2007.

20. Tyagi A, Vishnoi K, Mahata S, Verma G, Srivastava Y, Masaldan S, Roy BG, Bharti AC and Das BC: Cervical cancer stem cells selectively overexpress HPV oncoprotein E6 that controls stemness and self-renewal through upregulation of HES1. Clin Cancer Res 22: 4170-4184, 2016.

21. Bidaux G, Borowiec AS, Gordienko D, Beck B, Shapovalov GG, Lemonnier L, Flourakis M, Vandenberghe M, Slomianny C, Dewailly E, et al: Epidermal TRPM8 channel isoform controls the balance between keratinocyte proliferation and differentiation in a cold-dependent manner. Proc Natl Acad Sci USA 112: E3345-E3354, 2015.

22. McIver SC, Katsumura KR, Davids E, Liu P, Kang YA, Yang D and Bresnick EH: Exosome complex orchestrates developmental signaling to balance proliferation and differentiation during erythropoiesis. Elife 5: e17877, 2016.

23. Monje PV: To myelinate or not to myelinate: Fine tuning cAMP signaling in Schwann cells to balance cell proliferation and differentiation. Neural Regen Res 10: 1936-1937, 2015.

24. Brandenberger R, Wei H, Zhang S, Lei S, Murage J, Fisk GJ, Li Y, Xu C, Fang R, Guegler K, et al: Transcriptome characterization elucidates signaling networks that control human ES cell growth and differentiation. Nat Biotechnol 22: 707-716, 2004. 
25. Niwa $\mathrm{H}$ : Molecular mechanism to maintain stem cell renewal of ES cells. Cell Struct Funct 26: 137-148, 2001.

26. Wall DS, Mears AJ, McNeill B, Mazerolle C, Thurig S, Wang Y, Kageyama R and Wallace VA: Progenitor cell proliferation in the retina is dependent on Notch-independent Sonic hedgehog/Hes1 activity. J Cell Biol 184: 101-112, 2009.

27. Sun L, Liu M, Sun GC, Yang X, Qian Q, Feng S, Mackey LV and Coy DH: Notch signaling activation in cervical cancer cells induces cell growth arrest with the involvement of the nuclear receptor NR4A2. J Cancer 7: 1388-1395, 2016.

28. Wu X, Liu W, Tang D, Xiao H, Wu Z, Chen C, Yao X, Liu F and Li G: Prognostic values of four Notch receptor mRNA expression in gastric cancer. Sci Rep 6: 28044, 2016.

29. Moore MA and Tajima K: Cervical cancer in the asian pacificepidemiology, screening and treatment. Asian Pac J Cancer Prev 5: 349-361, 2004.

30. Parkin DM, Bray F, Ferlay J and Pisani P: Estimating the world cancer burden: Globocan 2000. Int J Cancer 94: 153-156, 2001.

31. Jemal A, Thomas A, Murray T and Thun M: Cancer statistics, 2002. CA Cancer J Clin 52: 23-47, 2002.

32. Cuschieri K, Brewster DH, Graham C, Nicoll S, Williams AR, Murray GI, Millan D, Johannessen I, Hardie A and Cubie HA: Influence of HPV type on prognosis in patients diagnosed with invasive cervical cancer. Int J Cancer 135: 2721-2726, 2014.
33. He D, Duan C, Chen J, Lai L, Chen J and Chen D: The safety and efficacy of the preoperative neoadjuvant chemotherapy for patients with cervical cancer: A systematic review and meta analysis. Int J Clin Exp Med 8: 14693-14700, 2015.

34. Yu JQ, Zhou Q, Zhu H, Zheng FY and Chen ZW: Overexpression of astrocyte elevated gene-1 (AEG-1) in cervical cancer and its correlation with angiogenesis. Asian Pac J Cancer Prev 16: 2277-2281, 2015.

35. Cenciarelli C, Marei HE, Zonfrillo M, Casalbore P, Felsani A, Giannetti S, Trevisi G, Althani A and Mangiola A: The interference of Notch1 target Hes1 affects cell growth, differentiation and invasiveness of glioblastoma stem cells through modulation of multiple oncogenic targets. Oncotarget 8: 17873-17886, 2017.

36. Phillips NE, Manning CS, Pettini T, Biga V, Marinopoulou E, Stanley P, Boyd J, Bagnall J, Paszek P, Spiller DG, et al: Stochasticity in the miR-9/Hes1 oscillatory network can account for clonal heterogeneity in the timing of differentiation. Elife 5: e16118, 2016.

37. Orphanides G and Reinberg D: A unified theory of gene expression. Cell 108: 439-451, 2002. 